\title{
Meaning, Moral Realism, and the Importance of Morality*
}

\author{
Michael Zhao \\ (In Philosophical Studies 117 (2020): 653-666; please cite published version)
}

\section{Introduction}

Some philosophers have the sense that morality loses some of its significance if there is no realm of objective moral fact. If morality is just grounded in our emotions, the thought goes, then its demands cannot have absolute authority over us; only the hardness of metaphysical fact can support the hardness of the moral "ought." And so the normative importance of morality seems to depend on moral realism, the view that there are mind-independent moral truths. ${ }^{1}$ As Derek Parfit $(2011,425)$ put it (rather bleakly),

If there were no such truths, there would be no point in trying to make good decisions. Nothing would matter, and there would not be better or worse ways to live.

Similarly, philosophers from the existentialist tradition have been impressed by the fact that many people feel that morality ceases to matter when they discover the ideality of values (read: anti-realism). In other words, acts seem to lose their exigency when we realize that a command to perform them neither issues from God nor is woven into the fabric of the universe. So Sartre (1945) wrote:

*I am grateful to Anthony Appiah, Max Barkhausen, Camil Golub, Sam Scheffler, Sharon Street, members of the Extreme Value Theory Group at NYU, and an anonymous referee for insightful comments on earlier drafts of this paper.

${ }^{1}$ I intend this formulation to rule out views like constructivism, on which moral truths are ultimately mind-dependent, and also views like non-cognitivism, according to which (strictly speaking) there are no moral truths at all, since the function of moral language is not to describe such truths. 
It is nowhere written that "the good" exists, that one must be honest or must not lie, since we are now upon the plane where there are only men. Dostoevsky once wrote: "If God did not exist, everything would be permitted"; and that, for existentialism, is the starting point.

I take it that "permitted" here means permitted all things considered, rather than specifically permitted morally: if there is no source of objective values (because there is no God, for example), then there is no longer reason to be honest, or not to lie, or do anything else that is morally required. Of course, this is far too extreme a reaction to the rejection of moral realism. Sartre himself seems not to endorse this view fully, calling it only the "starting point" for further reflection. But it might be optimistic to think that, at the end of reflection, we will be able to recover all of the importance that we took morality to have when we believed in the existence of objective values.

At this point, however, one might wonder how realism was supposed to secure the importance of morality at all. Even if there were values laid out by God or woven into the fabric of the universe, couldn't we still choose to disregard them? There seems to be a connection between the existence of cosmic underwriting for moral values and the authority of those values over us, but it is not clear what the connection is.

In this paper, I want to vindicate a version of the suspicion that the normative importance of morality depends on moral realism. More specifically, I want to show that if teleological forms of moral realism-those that posit an objective purpose to human life, grounded in some important feature of the universeare true, then we will have a distinctive kind of reason to do what morality requires. ${ }^{2}$ In doing this, however, I will need to draw a contrast that has been largely neglected, between teleological versions of moral realism and the kind of non-naturalist realism familiar in modern-day meta-ethics. One implication of what I have to say is that neither anti-realism nor non-naturalist realism is able to secure the normative importance of morality.

Let me make this claim more precise in a few ways. First, $\mathrm{I}$ intend to argue that if teleological forms of realism are true, then the fact that an act is morally required gives us reason to perform it rather than merely indicates existing reason to perform it. So this view is distinct from a view on which we have reason to

\footnotetext{
${ }^{2}$ One terminological note: I'm not using "teleology" in the sense that some moral philosophers use it, to indicate moral theories (like consequentialism) that specify the good independently of the right. Instead, I'm using "teleology" to talk about the purposes of things.
} 
do what morality requires only because we have independent reason to do the specific things that it actually requires: to help others, to refrain from harming them, to be just, and so on. Instead, the claim that I have in mind implies that if teleological realism is true, then we have reason to do whatever is morally required, rather than only to do the things that are actually morally required: in other words, we have reason to do what is morally required, on a de dicto rather than a de re reading of that claim. (Throughout, I will use "normative importance" to mean that a set of requirements is reason-giving in this way.) $)^{3}$

Second, I am using "reasons" in Bernard Williams (1979)'s sense of internal reasons, those than an agent can arrive at through a sound deliberative process from his subjective concerns. This is to distinguish my view from those on which the importance of morality comes cheap: certain forms of moral realism, for example, might just include an auxiliary claim to the effect that we have reason to do what morality asks of us. Christine Korsgaard $(1996,33)$ accuses such forms of realism of trying to answer the normative question-why we should do what morality tells us to do-simply by fiat, by positing the existence of intrinsically normative facts. Focusing on internal reasons circumvents this problem: to show that morality has normative importance in the internal sense requires not just positing the normativity of morality, but showing how it links up to existing concerns that we have. (That said, I don't want to say that we have no external reason to do what morality requires if teleological realism is false; rather, I simply want to avoid discussions of external reasons altogether.)

My use of internal reasons might seem to conflict with what I have about the reason-giving quality of moral facts. But the conflict is only apparent: claims that we have internal reason to do something and that moral facts are reason-giving

\footnotetext{
${ }^{3}$ Why think that the normative importance that people attribute to morality is reason-giving rather than merely reason-indicating, though? One might think that we have reason to do what morality requires simply because we have reason to do the specific things that morality requires, like helping others or not harming them, and we have reason to do these things because the promotion of well-being or respect for others' autonomy is intrinsically important. If the intuition is simply that morality has importance in this reason-indicating sense, then we do not need teleological realism to secure its importance: other meta-ethical views that attribute importance to things like the promotion of well-being or respecting others' autonomy will do.

In response, note that this would not allow for the possibility of the motive of duty: that is, being motivated to do something by the mere thought that it is the right thing to do. When people are motivated by this thought alone, then presumably they think that the mere fact that an act is right provides them with reason to perform it; the belief that they have reason to perform the act then motivates them to perform it. If this is correct, then people must take morality to have importance in the reason-giving rather than (merely) reason-indicating sense.
} 
(rather than only reason-indicating) track two separate dimensions of counterfactual variation. It is possible that the fact that an act is morally required gives us reason to perform it, but also that its reason-giving quality is enabled by our having certain subjective concerns. (Analogously, the fact that a young child's mother has told him to do something might give him reason to do it, even if he has reason for that only because he is afraid that she will punish him if he does not.)

So here is the claim that I want to defend in this paper: If teleological forms of realism are true, then the fact that an act is morally required gives us internal reason to perform it. In contrast, if anti-realism or non-naturalist realism is true instead, then we have no reason to think that moral facts give us internal reasons for action. I plan to demonstrate this by showing that if and only if teleological forms of realism are true, then doing what is morally required (whatever that turns out to be) can connect us to something larger and more significant than ourselves. This can infuse our lives with meaning, so that anyone with concern for meaning has reason to follow moral requirements. This would be a way of securing the importance of morality by showing how we can incorporate a concern for its requirements into a eudaimonic perspective.

I admit that this is not a reason that exists for all human beings or rational agents. Nonetheless, the desire for meaning is something that is part of the psychology of many people: we want our lives to be connected to what matters in the grand scheme of things, rather than to be frictionless orbs adrift in ethical space. For most of us, then, such a concern will give us reason to do what morality requires if the forms of realism that I have in mind are true.

Let me outline the paper. In sections one and two, I lay out and discuss the ingredients of the argument. Because the argument rests heavily on the idea that morality can provide a life with meaning, I give, in $\$ 1$, an account of a life's having meaning. And in $\$ 2$, I spell out teleological moral realism and contrast it with a version of moral realism that is more familiar to modern meta-ethics. Next, in $\$ 3$, I argue that if teleological moral realism is true, then doing whatever is morally required can provide a life with meaning, so that (given that we desire meaning) we have reason to do whatever is morally required. In $\$ 4$, I argue that neither anti-realism nor non-naturalist realism can support the normative importance of morality in a similar way. These two claims establish that the normative importance of morality depends on the truth of teleological realism. Finally, in $\$ 5$, I respond to objections.

William Frankena (1973) wrote that "morality is made for man, not man for morality." But if the forms of realism that I have in mind are true, this dichotomy 
might be simplistic: man might follow morality for the reason that, in doing so, he gives his own life meaning.

\section{Meaning}

Let me start, then, by discussing meaning. I want to note that when ordinary people talk about "meaning in life" or "the meaning of life," they might have a number of things in mind. Nonetheless, I take it that there is one important cluster of ideas that people often have in mind when they talk about meaning, which I will look at in this section.

As a preliminary, I want to distinguish between meaning and a sense of purpose, which I understand to be a set of dispositions to pursue a goal and to feel satisfaction or disappointment if one succeeds or fails at that goal. Colloquially, having a life with meaning is different from merely having something that one lives for. Playing video games or linking an entire box of paperclips can provide a person with a sense of purpose, if only temporarily, although they are fairly meaningless pursuits. At a purely physiological level, taking certain kinds of stimulants can give someone a sense of purpose for a few hours, although it surely does not make one's life more meaningful for that duration. Even a sustained sense of purpose, something that animates a person's entire life, might not be enough to give that life meaning: someone might endure the day-to-day with the belief that it will allow him to retire comfortably one day; but we have the intuition that such a life would not thereby have much meaning. Conversely, although it is harder to think of cases here, one can live a life that has important components of meaning without having much of a sense of purpose: an artist might be painting what will be recognized centuries later as an artistic masterpiece, although he finds work on the piece completely unrewarding and works on it only because he needs to pay off his debts. Of course, what provides many people with a sense of purpose in life-say, some creative, scholarly, or humanitarian endeavor-is something that is meaningful; but meaning and a sense of purpose can clearly come apart.

If there is no necessary connection between having a sense of purpose and meaning, then what does meaning amount to? In answering this question, I want to draw on one cluster of views held by different philosophers who have discussed the question. What these views share is the idea that a life receives meaning by engaging in, or being positively connected to something that is an appropriate object of positive attitudes like valuing, love, or awe. Robert Nozick $(1981,610)$, for example, writes: "Meaning involves transcending limits so as to 
connect with something valuable." Similarly, Charles Taylor (1989) proposes that, in order for something to have meaning, it must merit emotions like love, awe, and so on; what gives our lives meaning must be something that is lovable or awe-inspiring. In the same vein, Susan Wolf $(2010,8-9)$ writes that "meaning arises from loving objects worthy of love and engaging with them in a positive way... meaning arises when subjective attraction meets objective attractiveness."

Instead of talking about something's being an appropriate object of a group of attitudes (valuing, love, awe, attraction, and so on), I'll just say that that thing is important or matters. This difference in terminology is purely for the sake of simplicity, and I don't intend what I say to conflict in a substantive way with any of the accounts that I just mentioned. In these terms, what is necessary for a life to have meaning is that it engage in, or be positively connected to something that matters. ${ }^{6}$ I will call this condition-connection to or participation in something that is important-significance. My claim, then, is that significance is at least one important component of meaning.

As one piece of evidence that significance is a condition on meaning, let us consider some paradigmatic examples of lives that are meaningful, and ones of those that are meaningless. Consider, for example, someone who devotes her life to humanitarian work, who works to eradicate a widespread disease, or to break the cycle of poverty in a destitute region of the world; or think of someone who dedicates his life to creative or scholarly pursuits, who creates innovative works of art or makes theoretical breakthroughs in a field of study. Most of us think that these people have meaningful lives. Why? Because their lives are positively connected to-they advance-certain important projects: the eradication of disease, the creation of a new art form, scientific discovery, and so on. In contrast, consider someone who lives a paradigmatically meaningless life: we might think of someone who lacks deep relationships with other people, who does not contribute to his community, who lacks interesting hobbies, and who neglects self-development. We find his life meaningless precisely because he is not connected, in any significant way, to anything that matters. In our terms, his life lacks significance, while the paradigmatically meaningful ones have it. So significance seems to be one important part of what we have in mind when we

\footnotetext{
${ }^{4}$ Italics mine.

${ }^{5}$ Italics mine.

${ }^{6} \mathrm{I}$ 'm going to remain neutral on the meta-ethics of mattering or being important. Although moral realism is congenial to realism about mattering, we need not endorse the latter view in order to get the account going. Similarly, I'm not going to provide anything like a theory of what matters; I'll simply rely on intuitions that ordinary people have.
} 
say that a life is meaningful.

Of course, perhaps people also have other things in mind when they talk about meaning. People often speak of "the meaning of life," as if it were the solution to a puzzle; perhaps they also have in mind something that can provide one with a sense of clarity, an understanding of why one exists and what one should do. But this sense of meaning is more obscure, and I will put it aside, without intending to rule it out.

\section{Two kinds of moral realism}

Now, the main claim of the paper is that the normative importance of morality depends on the truth of a specific form of moral realism, since the truth of that kind of realism allows doing what is morally required to give our lives meaning. Having finished discussing meaning, I want now to get clear on the version of realism that $\mathrm{I}$ have in mind.

I want to start by drawing a contrast to the familiar kind of non-naturalist realism that has currency in meta-ethics nowadays. Modern-day non-naturalist realism makes two claims: (1) there are objective moral facts; (2) moral properties are irreducible to non-moral properties, and moral facts are distinct from other kinds of facts. So according to non-naturalist realism, morality is objective and sui generis, autonomous from and discontinuous with other subject matters. ${ }^{7}$ Russ Shafer-Landau $(2003,55)$, for example, writes that "it appears that moral values are something very different in kind from anything else that we are familiar with," and suggests that we "take [this appearance] at face value, and introduce into our ontology a sui generis category of values." And David Enoch $(2011,4)$ defines his favored position, Robust Realism, as "the thesis that there are objective irreducibly normative truths." (Of course, Enoch is talking about normative realism in general rather than moral realism, but we can extend his definition to moral realism.)

Note that proponents of non-naturalism have resisted saying much about what morality is supposed to be, say, by connecting it to some other subject matter. Of course, we are told that moral facts are objective and normative, but often not much positive is said beyond that. In this regard, non-naturalist realists are like negative theologians, trying to describe God in terms of the qualities he lacks (e.g., being spatio-temporally located) rather than has. (Think of the termi-

\footnotetext{
${ }^{7}$ I want to note that I'm excluding divine command theory, which grounds moral properties in supernatural (hence non-natural) properties, from "non-naturalist realism." I'm using the term to pick out the kind of view popular in meta-ethics nowadays, according to which moral properties are non-natural and distinct from all other kinds of properties.
} 
nology: moral properties are non-natural; they are sui generis, unlike anything else.)

In contrast, the teleological forms of moral realism that I have in mind are package deals, comprising a metaphysics and a substantive moral theory. They present morality as being continuous with theology, or cosmology, or biology. Such views are positive, embodying a conception of human life: first, they present a picture of how humanity fits into the universe as a whole, one that involves the intentions of God or some important aspect of the universe itself; second, they claim that there is an objective purpose to human life that is grounded in these things, and whose content is connected in a straightforward way to the location of humanity in the universe; finally, they claim that morality is a matter of living in accordance with the purpose of human life. ${ }^{8}$ (I'm using "purpose" differently here, of course, from how I use it in "sense of purpose.") At this point, let's not stipulate that purposes are intrinsically normative, so that we automatically have reason to live in accordance with our purpose; that would be doing what Korsgaard criticizes, making morality normative by fiat. Nonetheless, notice that purposes amount to requirements on human life (whether or not we have reason to obey them) from God or some important feature of the universe.

Such forms of moral realism embody a conception of morality as a matter of living in accordance with the purpose of the kind that one belongs to. Accordingly, the basic moral terms will not be thin ones like "right" or "wrong," but ones describing a match or mismatch between one's behavior and purpose: "fitting" and "not fitting," "appropriate" and "inappropriate." In the remainder of this section, I want to mention briefly a few examples of such views.

Take, first, a traditional Christian conception of human life. On this account, an all-powerful god created human beings (different traditions tell different stories here) for his glory, for companionship, or to help carry out his plan for creation. (Take Isaiah 43:7: "Even every one that is called by my name: for I have created him for my glory, I have formed him.") Hence God is both the source of the purpose of human life and part of its content: God's intentions ground

\footnotetext{
${ }^{8}$ I don't want to lean too much on the term "moral"; it's conceptually possible for the content of morality on this way of defining it to be quite different from what we typically take it to be, as having to do with things like our obligations to other people. (One could imagine a possible world in which the purpose of human life is to link as many paperclips together as possible; in such a world, what morality requires us to do has nothing inherently to do with our behavior toward others.) Nonetheless, what fulfilling the purpose of human life involves on the views I consider overlaps considerably with morality, in the usual sense, so I'm not just changing the subject here.
} 
the purpose of human life, and that purpose involves him centrally. Morality, on such a view, is just living in accordance with this divinely-intended purpose: what is appropriate for human beings is to glorify God, to act in accordance with his plans, to keep his laws, and so on.

Turn now to Stoicism. It is tempting to read the Stoics as simply offering practical advice for maintaining your tranquility in a world shot through with chance, but that was not the intention behind their teachings. Rather, their ethics derives from their metaphysics. According to their metaphysical system, God is identical to reason $(\log o s)$, the active substance of the universe; the evolution of the universe itself is the result of reason's acting on the passive substance, matter, in accordance with the principles contained in the former. Hence there is something like a divine plan for the universe, although (unlike in Christianity) this plan is immanent in the universe itself. So the purpose of human life (and the purpose of everything else) is to live in accordance with these principles of cosmic evolution. Since everything that happens is a manifestation of this, not wanting things to go differently from how they actually go is a sign of submission to the underlying principles of the universe: a sign that one knows one's place, so to speak. ${ }^{9}$

Now, take classical Confucian ethics. Here, the source of morality is Heaven (tian), conceived of as a personal deity or (in later times) as the natural order of things. ${ }^{10}$ According to this view, the social order reflects the intentions or structure of Heaven, so the purpose of human life is to play the roles appropriate to the social position that one finds oneself in: "Let the ruler be a ruler; the minister, a minister; the father, a father; the son, a son."11

Finally, let's look at Aristotelian ethics. Aristotle held that the purpose of human life is picked out by the activities that make human beings distinctive from other forms of life, and he took this to be rational activity. Hence it is appropriate for human beings to act rationally, and living a good life is exercising the rational capacity in accordance with certain forms of excellence. It is controversial whether Aristotle thought that anything unified grounds that purpose. $\mathrm{He}$ clearly thinks that the purpose of human life issues from our nature, but he seems to think (e.g., in The Metaphysics) of nature as belonging to individuals: an inner principle of development, rather than a unified feature of the cosmos. Nonetheless, Aristotle talks of natural justice and certain political systems as "naturally

\footnotetext{
${ }^{9}$ See, for example, Nicholas White's introduction to his translation of Epictetus' Handbook.

${ }^{10}$ See, for example, Louden (2002).

${ }^{11}$ Analects 12:11.
} 
best, ${ }^{\prime 2}$ so he seems to think that nature is important-it is an appropriate object of respect-even if it is individualized rather than unified.

The descriptions of these moral views are admittedly cursory. I provide them, however, simply to illustrate a general phenomenon, fully aware that I have simplified or omitted important features about each view. Again, the views share several components: (1) important, high-level features of human life are explained in terms of God's intentions or important aspects of the universe itself; (2) these things ground an objective purpose to human life, whose content has to do with the features explained; (3) it is morally appropriate for human being to live in accordance with this purpose. In other terms, these views say that the nature of morality consists in requirements on human life generated by God, nature, etc.; the content of morality is to fulfill the purpose of human life, which consists in living in accordance with God's plan, wanting things to go as they do, acting rationally, performing one's social roles, and so on.

Notice again how much these forms of moral realism differ from the realism that many modern-day philosophers hold, the bare thesis that there are mindindependent moral facts, distinct from and irreducible to other kinds of facts. Non-naturalist realists make no effort to locate a source for morality, nor do they try to connect it to a philosophical anthropology, an account of what human beings are and what their purpose is. Perhaps non-naturalist realism is more plausible precisely because it has less baggage; but, as the next section will show, because it lacks the additional commitments, we have no reason to think that it can allow doing what is morally required to provide one's life with meaning, and so secure the normative importance of morality either.

\section{How teleological realism secures the importance of morality}

I have discussed the notion of meaning that I have in mind, and distinguished the teleological forms of realism that I want to focus on from non-naturalist realism. In this section, I want to argue that if the teleological forms of realism that we discussed are true, then doing what is morally required-that is, living in accordance with the purpose of human life, whatever that is-provides meaning. I also want to show, in the next section, that if rival meta-ethical views (like anti-realism or non-naturalist realism) are true instead, no such obedience to morality can provide meaning, whatever the prospects of deriving meaning from other routes are. This means that, for people who have a desire for meaning, teleological moral realism will secure a distinctive reason to do what morality requires, one that

\footnotetext{
${ }^{12}$ Nicomachean Ethics, V.7.
} 
does not exist if either anti-realism or non-naturalist realism is true instead. The upshot is that if teleological realism is true, then morality has normative importance; conversely, if it is false, then we have no reason to think that morality has normative importance.

Recall the conception of meaning that we are interested in, meaning as significance: in order for my life to have meaning, it must be connected in a positive way to something important. Now, consider the teleological forms of moral realism that we just discussed, each of which assigns a purpose to human life. As we discussed, that purpose amounts to a requirement on human life established by God or some aspect of the universe itself, which are things of importance: they are objects that merit our respect or awe. So in living in accordance with the purpose of human life, whatever that purpose is, I fulfill a requirement set by an entity of importance, thereby connecting myself positively with that important entity. In living in accordance with the divine plan, or submitting to the cosmic flow, or performing my social roles, I am doing what God or Nature requires of me, which creates a positive connection between me and God or Nature. So according to these views, my life gains significance, hence meaning, by my acting in accordance with the purpose of human life: that is, by my doing whatever is morally appropriate.

Notice that what does the work here is not any intrinsic authority that whatever gives human life its purpose has; in other words, I am not securing the normativity of morality simply by building normativity into its source. I am not assuming that, in advance of any desires or goals that we have, we have reason to obey God or to live in accordance with Nature. Rather, I am assuming only that whatever gives human life its purpose, on the versions of teleological realism that we considered, is an appropriate object of positive attitudes like love, awe, valuing, and so on. Nor is this an attempt to explain the importance of morality simply by positing a source with importance, on the reading of this claim in which "importance" has the same meaning throughout. Disambiguating, I am trying instead to show that we have reason to do what morality requires because it is underwritten by a feature of the universe that merits our love or awe.

Now, my argument requires attributing a widespread desire for meaning to human beings, and one might object that this smacks of intellectualization. People do not seek meaning, the objection goes; only philosophers (or angsty teenagers or depressives) do that. I concede that ordinary people may only seldom talk about meaning; nonetheless, it does seem to have the importance of a need for many. After all, many people do want their lives to contribute to the big picture. (This is why reflection on the ultimate demise of humanity, or even 
more mundane things, like civilizational decline-in short, anything that makes us aware of how small a part of the big picture anything that we could contribute to makes up-can be profoundly unsettling: it makes us think that the grounds of the meaning in our lives are themselves meaningless.) Perhaps talk of meaning is limited precisely because most people think their lives are meaningful enough, so that it's only when we feel disoriented or depressed that we consciously look for meaning.

\section{Does morality have importance without teleological realism?}

One might wonder if rivals to teleological moral realism can secure the normative importance of morality in the same way. I want to argue that, if anti-realism or non-naturalist realism is true, then it is not true that doing whatever morality requires provides our lives with meaning. If this is so, then we have no reason to think that either anti-realism or non-naturalist realism can secure the importance of morality. Let me discuss anti-realism first, then non-naturalist realism.

First, note that if anti-realism is true, morality is no longer something that is metaphysically underwritten by any important feature of the universe. After all, anti-realists will say that moral truths are constituted by being the outputs of some deliberative procedure, or that moral claims express non-cognitive states, and so on. On any of these stories, the source of morality is not an entity that has objective importance. ${ }^{13}$ So in doing what is morally required on the antirealist picture, we are not thereby connecting ourselves to anything that could provide our life with meaning. Hence anti-realism does not secure the normative importance of morality in the same way that teleological realism does.

One might think that there are other ways my life could still have meaning through some connection to morality, even if anti-realism is true. Moral philosophers, for example, have sometimes talked about the ability of morality to provide meaning because of its content. Morality might recommend, for example, a life devoted to the good of mankind; in living such a life, I derive meaning from being positively connected to the well-being of others, which is something that matters.

The problem with this is that it shows that we have reason only to do the specific things that are morally required, rather than to do what is morally required as such. It therefore cannot vindicate the normative importance of morality, its

\footnotetext{
${ }^{13}$ Pace Kant's remark that the moral law within is a constant source of awe, I take it that most people would not think that merely meeting the requirements of Kantian rationality would give their lives meaning.
} 
giving us reason for certain acts rather than merely indicating that we have reason to perform those acts. Put another way, we can derive meaning through being moral because the content of morality is what it actually is; but teleological realism allows doing what is morally required to provide meaning in a different way, not through the content of moral requirements, but simply through their nature: a set of prescriptions that are underwritten by God or the universe.

So this is not to deny that there are other routes to meaning if anti-realism is true. I can still derive significance by connecting my life to things of importance. What I deny is simply that doing what is morally required (read de dicto) can provide meaning if anti-realism is true. This does mean, however, that one important reason to do what morality requires if teleological moral realism is true will be absent if anti-realism is true instead.

Now, one might think that this concedes too much. If there are more mundane routes to meaning, then this undermines the importance of morality even if teleological forms of realism are true. After all, if my life already has meaningif I am already working toward important goals-then why do what morality requires, if the relevant reason for doing so is that it will provide my life with meaning? Why should the humanitarian working to eradicate a widespread disease, or the scientist who makes great advancements to human knowledge, care about what God or Nature requires? In response, notice that significance is gradable rather than binary: something can be more significant than another, even if they are both significant to some degree. Insofar as the significance of my life depends on the importance of whatever it is connected to or engages in, my life has much more significance if that thing is as all-encompassing as God or the universe. So doing what morality requires, if teleological realism is true, can still provide my life with additional meaning even once it has some meaning, and my reason for doing what it requires is not undermined by the presence of meaning in my life.

Finally, I want to argue that non-naturalist moral realism does not secure the normative importance of morality in the way that teleological moral realism does. First, note that we have no reason to think that morality is something of intrinsic importance if non-naturalism is correct, precisely because non-naturalism does not say much about the nature of moral requirements. It does not, for example, ground moral properties in properties of some subject matter whose importance we have clear intuitions about. Given that moral values are sui generis, what reason do we have to think that they are like any of the other things that we consider important? And second, the claim that something is of importance is a striking claim: after all, the proportion of things that are appropriate objects 
of love or awe is low, so we should start off with a low credence that some given thing has importance. The burden of proof, then, is on the non-naturalist to show that morality is something of importance, and I have just argued that they have not done this.

Note that this does not establish with anything like certainty that morality lacks importance if non-naturalist realism is correct. But in the absence of any reason to think that it does have such importance if non-naturalist realism is correct, we should think that it does not. So I conclude that if non-naturalism is true, then doing what is morally required would not thereby give our lives meaning.

Nonetheless, most people through human history have accepted (if tacitly) a more substantive form of moral realism, on which morality is supported by an entity that has importance. The acceptance of the familiar kind of non-naturalist realism, on the other hand, has taken off only recently, and is confined largely to philosophers. In light of this, we might conjecture that the loss of meaning that many people experience when they come to abandon moral realism is really a response to abandoning the teleological forms of realism that I have discussed. When we see that moral requirements do not have their source in anything that is an appropriate object of love or awe, we see that our lives do not gain meaning by following them, and lose part of the reason that we took ourselves to have to follow them in the first place.

In fact, it is easy to construct a story for why modern-day non-naturalist realism gives morality the appearance of normative importance or authority, even if it really lacks it. In other words, if non-naturalist realism is true, then it is easy to explain away our intuition that morality has authority at all. On this story, morality inherits the appearance of authority from traditional, more substantive conceptions of morality on which its source is some significant feature of the universe, from which morality is supposed to derive its authority. But while nonnaturalist realism gives up the idea that morality is connected to any such source, it has not yet given up the idea that morality has authority. All of this confirms Anscombe (1958)'s claim that, in the aftermath of the death of teleology, the moral "ought" has become "a word of mere mesmeric force," one that has no real meaning anymore, but that is still able to draw on its old emotional associations.

\section{Objections}

One objection to the overall argument is that there might be widespread desires other than those for meaning that can make moral facts reason-giving without 
relying on teleological realism. If so, then the normative importance of morality does not depend on teleological realism. One promising candidate for such a desire, for example, might be a desire to be a morally upright person: to do what is morally required of me, whatever that may be.

In response to such an objection, however, think about what such a desire would amount to if teleological realism is false, in other words, if morality does not have its source in any object of importance. In that case, the desire to do whatever is morally required would seem strange, being simply a desire to follow a set of disembodied commands. And we might wonder whether anyone, upon full reflection, would endorse such a desire at all.

In a similar vein, Michael Smith $(1994,75)$ notes that good people are typically motivated by substantive moral concerns, like the well-being of their loved ones, justice, equality, and so on, rather than by the mere thought that something is morally required. "Indeed," he writes, "commonsense tells us that being so motivated [to do what is morally required as such] is a fetish or moral vice, not the one and only moral virtue." Doing what is morally required simply because it is morally required-at least, in the absence of any background story about the importance of moral requirements as such - might seem fetishistic or perverse. And to the extent that we think that such a desire is a vice, we might think that the desire does not give us reason to fulfill it, since any normative force that it has is canceled by the fact that it is a vice.

Why wouldn't my own view, though, be vulnerable to this point? After all, I am trying to show that if teleological realism is correct, then we have reason to do what morality requires de dicto, and this seems equally open to the charge of fetishizing morality. But in response to this point, note that teleological realism has a fuller story to tell about the nature of moral requirements: for something to be morally appropriate is for it to be in accordance with the objective purpose of human life. In being motivated by the belief that an act is morally required, I am motivated by the belief that the act is required of me by some important entity or feature of the universe, and by a feeling of love or awe toward that entity. Now, a fetish is inordinate concern for something, and it is not inordinate to be motivated by love or awe toward what merits it: to fear God or to submit to the cosmic flow, assuming that such things really exist. So being motivated to do what is morally required as such, if teleological realism is true, need not fetishize morality. 


\section{Conclusion}

Let me conclude. I have argued that teleological forms of moral realism, those framed in terms of an objective purpose of human life, can secure the normative importance of morality. I have argued for this by showing that, if these kinds of realism are true, then doing what is morally required can provide a life with meaning, a widespread human need. After all, meaning arises when I positively connect my life to an object of importance, and these views present morality as having its source in exactly those objects. I have also argued that nothing similar is possible if anti-realism or non-naturalist realism is true: rival views preserve the name of morality, but the name signifies nothing that could command devotion. 


\section{References}

Elizabeth Anscombe. "Modern Moral Philosophy." Philosophy, 33(124), 1958.

David Enoch. Taking Morality Seriously. Oxford University Press, 2011.

William Frankena. Ethics. Prentice-Hall, 1973.

Christine Korsgaard. The Sources of Normativity. Cambridge University Press, 1996.

Robert Louden. “'What Does Heaven Say?': Christian Wolff and the Western Interpretations of Confucian Ethics." In Bryan van Norden, editor, Confucius and the Analects: New Essays. Oxford University Press, 2002.

Robert Nozick. Philosophical Explanations. Harvard University Press, 1981.

Derek Parfit. On What Matters, Vol. 2. Oxford University Press, 2011.

Jean Paul Sartre. "Existentialism is a Humanism.” 1945.

Russ Shafer-Landau. Moral Realism: A Defence. Oxford University Press, 2003.

Michael Smith. The Moral Problem. Blackwell, 1994.

Charles Taylor. Sources of the Self. Harvard University Press, 1989.

Bernard Williams. "Internal and External Reasons." In Ross Harrison, editor, Rational Action. Cambridge University Press, 1979.

Susan Wolf. Meaning in Life. Princeton University Press, 2010. 